\title{
Guangdong-Hong Kong-Macau Greater Bay Area's Construction promotes the Economic Development of Guangdong in the New era
}

\author{
Wenyong Li ${ }^{1, a}$, Xueyu Zhang ${ }^{1, b}$ \\ ${ }^{1}$ Huali College Guangdong University of Technology, Guagzhou, China
}

\begin{abstract}
The construction of urban agglomeration and regional economic integration have become a new trend of regional economic development in China. Bay area economy is an important force to drive regional development and lead technological innovation. Guangdong-Hong Kong-Macau Greater Bay Area arises at the historic moment. By analyzing the demonstration effect of the experience and characteristics of the construction of the international three major bay areas on the construction of Guangdong-Hong Kong-Macau Greater Bay Area, this paper analyzes the characteristics and advantages of Guangdong-Hong Kong-Macau Greater Bay Area in the process of development, and puts forward the main measures to promote the economic development of Guangdong in the new era.
\end{abstract}

\section{Introduction}

The development of Guangdong-Hong Kong-Macau Greater Bay Area has been brewing for more than 10 years, and the concept was formally put forward in 2015. On February 18,2009, the CPC Central Committee and the State Council formally issued the outline of GuangdongHong Kong-Macau Greater Bay Area's Development Plan, marking the full implementation of Guangdong-Hong Kong-Macau Greater Bay Area's national strategy and Guangdong-Hong Kong-Macau Greater Bay Area's official launch.

The Guangdong-Hong Kong-Macao Greater Bay Area, which includes nine cities of Guangdong provincGuangzhou, Shenzhen, Zhuhai, Foshan, Huizhou, Dongguan, Zhongshan, Jiangmen and Zhaoqing as well as the Hong Kong SAR and the Macao SAR, covers an area of 56,000 square kilometers (Figure 1). With a total population of about 70 million at the end of 2017, the GDP of the region in 2017 was 101,843 trillion yuan (RMB), exceeding 10 trillion yuan (RMB) for the first time, accounting for $0.59 \%$ of the country's land and $4.89 \%$ of the population. It has created $13 \%$ of the total economic output of the whole country (including Hong Kong and Macao), and it is one of the regions with the highest degree of openness and the strongest economic vitality in China.

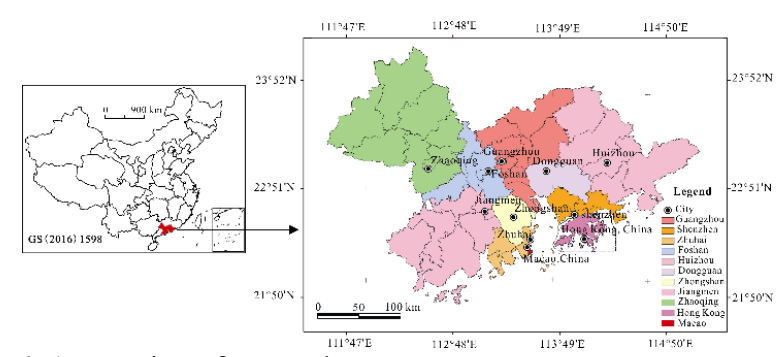

Fig1. Location of Guangdong-Hong Kong-Macau Greater Bay Area.

\section{The demonstration effect of the experience and characteristics of the three International Bay areas on the Construction of Guangdong-Hong Kong-Macau Greater Bay Area}

The Bay area economy is a kind of regional economic form based on the seaport and making use of the resource advantages of the Bay area. With open economic structure, good traffic network conditions, efficient resource allocation ability and developed international communication network, it is the main development pole to drive the development of regional and international economy. ${ }^{[1]}$

\subsection{Strong scientific and technological innovation, bringing together outstanding innovative talents and research strength}

Tokyo Bay Area alone has gathered more than 1/5 universities in Japan, about $30 \%$ of university faculty, nearly $1 / 4$ of non-governmental research institutions and 
nearly $1 / 2$ of top technology companies. San Francisco Bay Area gathered a group of famous American institutions of higher learning and research institutions, more than 1 million scientific and technological personnel from all over the world, the emergence of Google, Apple, Intel and other high-tech enterprises.

\subsection{Developed producer services such as finance}

Tokyo Bay Area is the main concentration of banks in Japan, with the largest Tokyo Stock Exchange in Japan, accounting for $80 \%$ of Japan's securities trading volume. The San Francisco Bay Area is highly integrated with finance, and the venture capital of Silicon Valley is very mature. The New York Bay Area brings together the

Table1. Comparison of the basic situation between Guang world's largest New York Stock Exchange by market value and the third-largest Nasdaq Stock Exchange by market value, with six of the seven largest banks in the United States.

\subsection{Agglomeration of headquarters economy}

Some experts, scholars and businessmen vividly define Guangdong-Hong Kong-Macau Greater Bay Area as the fourth largest Bay area in the world, juxtaposed with the New York Bay Area, the San Francisco Bay Area, and the Tokyo Bay Area in Japan. ${ }^{[2]}$ The basic situation of Guangdong-Hong Kong-Macau Greater Bay Area is compared with that of the three major bay areas in the world as shown in Table 1. areas in the world.

\begin{tabular}{|c|c|c|c|c|}
\hline Oject & GBA & $\begin{array}{c}\text { Figure } 1 . \quad \text { New } \\
\text { York Bay area }\end{array}$ & $\begin{array}{c}\text { San Francisco } \\
\text { Bay area }\end{array}$ & Tokyo Bay area \\
\hline $\begin{array}{c}\text { Area } \\
\text { (Ten thousand } \\
\text { square kilometers) }\end{array}$ & 5.6 & 2.1 & 1.79 & 3.68 \\
\hline $\begin{array}{c}\text { Population } \\
\text { (Million) }\end{array}$ & 7000 & 2340 & 715 & 4347 \\
\hline $\begin{array}{c}\text { GDP } \\
\text { (Trillions of } \\
\text { dollars) }\end{array}$ & 1.36 & 1.45 & 0.82 & 1.80 \\
\hline $\begin{array}{c}\text { Per capita GDP } \\
\text { (Ten thousand yuan } \\
\text { RMB) }\end{array}$ & 2.04 & 6.2 & 11.5 & 4.1 \\
\hline Major Industries & $\begin{array}{c}\text { Manufacturing, } \\
\text { Finance, Trade, } \\
\text { Shipping }\end{array}$ & $\begin{array}{c}\text { Finance, Fashion, } \\
\text { Professional } \\
\text { services }\end{array}$ & $\begin{array}{c}\text { Science and } \\
\text { technology, } \\
\text { Professional } \\
\text { services } \\
\end{array}$ & $\begin{array}{l}\text { Manufacturing, } \\
\text { Finance, Science } \\
\text { and technology }\end{array}$ \\
\hline $\begin{array}{c}\text { Proportion of } \\
\text { tertiary industry } \\
(\%) \\
\end{array}$ & 62 & 89.5 & 82 & 83 \\
\hline $\begin{array}{c}\text { Container } \\
\text { throughput } \\
\text { (Ten thousand } \\
\text { TEU) } \\
\end{array}$ & 6520 & 465 & 227 & 766 \\
\hline $\begin{array}{l}\text { Number of top } 100 \\
\text { universities in the } \\
\text { world }\end{array}$ & 4 & 2 & 3 & 2 \\
\hline $\begin{array}{c}\text { Number of } \\
\text { headquarters of } \\
\text { Fortune 500 } \\
\text { Enterprises }\end{array}$ & 16 & 22 & 28 & 60 \\
\hline
\end{tabular}

From Table 1, we can obviously see that there are still great differences between Guangdong-Hong Kong-Macau Greater Bay Area and the other three major bay areas in the proportion of per capita GDP and tertiary industry. In recent years, the development of the New York Bay Area and the San Francisco Bay Area, the economy has been in a low growth level, but Guangdong-Hong Kong-Macau Greater Bay Area, as a new Bay area, is erupting its own passion and vitality.

The international three major bay areas have perfect transportation facilities, high efficiency of interconnection, continuous improvement of development planning and improvement of the business environment.

\section{Guangdong-Hong Kong-Macau Greater Bay Area has obvious characteristics and advantages in development}

\subsection{Obvious advantages of location characteristics}

The scope of Guangdong-Hong Kong-Macau Greater Bay Area regionalization is 9 cities in the Pearl River Delta, Hong Kong and Macao. It occupies the most advanced and convenient spatial geographical position in Chinese docking global market, and has a long foundation and advantages for the development of open economy. At the 
same time, it is in the middle of the Asia-Pacific region, which is the most dynamic in the international economy (in the Asia-Pacific region, it is located in the middle of the east-west direction as well as the north-south direction). Compared with the other two world-class bay areas in the Asia-Pacific region (Tokyo Bay Area and San Francisco Bay Area), the geographical advantage of the other two world-class bay areas in the Asia-Pacific region is more obvious.

\subsection{Multi-engine characteristic advantages of Urban agglomeration}

China has five Alpha-rated world cities (Hong Kong, Beijing, Shanghai, Taipei and Guangzhou), according to the GaWC 2016 list of the Globalization and World cities Research Group at Loughborough University in the UK. Guangdong-Hong Kong-Macau Greater Bay Area has two of them, as well as Beta Shenzhen. Looking at the worldclass Greater Bay area, it is necessary to have two or more high-level cities to produce the setting-off effect of worldclass urban agglomerations, such as New York-Boston in New York Bay Area, San Francisco-Los Angeles in San Francisco Bay Area and Tokyo-Osaka in Tokyo Bay area, etc.

Moreover, at present, the total economic output of Guangzhou, Shenzhen and Hong Kong is very close to each other, forming the unique multi-engine characteristics of Guangdong-Hong Kong-Macau Greater Bay Area.

\subsection{Advantages of Transportation Hub and passenger flow Logistics}

Among the global airports ranked by passenger throughput in 2017, Hong Kong, Guangzhou and Shenzhen. It ranks 8th, 13th and 33th in the world, respectively. It has become the largest airport cluster with the densest spatial layout and the largest sum of passenger throughput among the top 50 airports in the ranked. Among them, the growth rate of Guangzhou airport is higher than that of the other 12 airports before it, reaching $10.2 \%$.

In 2017, the total passenger throughput of the five major airports of Guangdong-Hong Kong-Macau Greater Bay Area (Hong Kong, Guangzhou, Shenzhen, Macao and Zhuhai) exceeded 200 million, and the throughput of cargo and mail was nearly 8 million tons. The transportation scale has exceeded the world-class airport groups such as New York, London and Tokyo, and is the first airport group in the Bay area of the world.

The design standard of Terminal 1 of the Hong Kong Airport is to handle 45 million passengers a day, but it has now reached 73 million. The expansion of Terminal 1 under construction is expected to be completed in 2020, and upon completion of the third runway system in 2024, it will receive 100 million passengers per year. Guangzhou Baiyun Airport Terminal 2 has been opened, the design standard is to handle 45 million passengers a day, in 2020 can enter the top 10 airports in the world.

Guangzhou Port is currently the sixth largest port in the world in terms of cargo throughput, while if container throughput is counted, Guangdong-Hong Kong-Macau Greater Bay Area accounts for three of the seven major ports in the world (Shenzhen, Port, Guangzhou). As a result, the total container throughput of Guangdong-Hong Kong-Macau Greater Bay Area far exceeds that of other bay areas in the world. In 2016, the total throughput of the three ports of Guangdong-Hong Kong-Macau Greater Bay Area alone was 62.47 million TEUs, far exceeding 4.65 million TEUs in the New York Bay area, 7.66 million TEUs in the Tokyo Bay area and 2.27 million TEUs in the San Francisco Bay area, 4.5 times that of the world's three major Bay areas combined. To be number one in the world.

\subsection{Great advantages of innovative vitality and potential}

In 2017, the number of PCT patent applications in China increased by $13.4 \%$, making it the only country with a double-digit increase. Guangdong grew $13.7 \%$, while Guangzhou grew $48.7 \%$ from a year earlier. Shenzhen accounted for $43.1 \%$ of the country's absolute volume, and Shenzhen and Guangzhou combined accounted for more than half of the country's total. The innovation of enterprises is ahead of China, and ZTE and Huawei have occupied the top position in the world in the number of international PCT patent applications for many years.

Guangdong-Hong Kong-Macau Greater Bay Area's R\&D spending accounts for $2.7 \%$ of GDP, at the same level as the United States and Germany. Guangdong-Hong Kong-Macau Greater Bay Area occupies an important position in the global innovation network, especially in Shenzhen-Hong Kong. In the 2017 Global Innovation Index report released by the World intellectual property Organization, Shenzhen-Hong Kong overtook the San Francisco Bay area, where Silicon Valley is located, to rank second in the global innovation cluster, after Tokyo Bay. It will lay a solid foundation for building the Guangzhou-Shenzhen Science and Technology Innovation Corridor and promoting Guangdong-Hong Kong-Macau Greater Bay Area to move towards the main bearing area of the world-class science and technology innovation center.

At the same time, the innovative potential of the system can not be ignored. Although Guangdong-Hong Kong-Macau Greater Bay Area is involved in "one country, two systems" and there are objective institutional differences, efforts need to be made to strengthen cooperation in co-operation and coordination. However, based on the strong inclusive cultural characteristics of the Pearl River Delta and the support of the central policy, this includes the deep potential of "hybrid advantage", which is pregnant with institutional innovation and gives full play to institutional innovation.

\subsection{Comprehensive advantages of Industrial structure}

In a certain sense, the function of Guangdong-Hong KongMacau Greater Bay Area is the synthesis of three functions: New York Bay Area, Tokyo Bay Area and San Francisco 
Bay Area. The most important feature of the Bay area of New York is the leading international financial center. Hong Kong is an important international financial center. The most prominent features of the Tokyo Bay area are the advanced manufacturing and port industries, Shenzhen, Dongguan, Foshan and other manufacturing platforms with global competitive advantages. The San Francisco Bay area has Silicon Valley and Biomedical Valley. Our Shenzhen and Guangzhou have a good foundation in these areas.

The sum of GDP in Guangdong-Hong Kong-Macau Greater Bay Area's 11 cities increased from 8.17208 trillion yuan in 2014 to 10.1843 trillion yuan RMB (About $\$ 1.5$ trillion) in 2017. It has surpassed Russia, the world's 12th largest economy (\$1.46 trillion), and is close to South Korea, the world's 11th largest economy.

\section{The main measures to improve the quality of Development in the Construction of Guangdong-Hong Kong-Macau Greater Bay Area in Guangdong}

\subsection{Strengthen regional innovation}

With the introduction of R\&D forces of international advanced industries, high-tech enterprises, multinational R\&D institutions, institutions of higher learning and scientific research institutions, As well as the cultivation of patented technology, the incubation of scientific and technological achievements, and the coordinated innovation of Guangdong-Hong Kong-Macau Greater Bay Area in the region and in the province and across regions, we will speed up the construction of the core functional area of the national independent innovation demonstration zone and strive to develop large-scale scientific and technological industries. We will speed up the formation of high-tech industrial clusters. We will strengthen support for innovation for small and mediumsized enterprises and cultivate more innovative enterprises with independent intellectual property rights and core competitiveness. Establish the market-based industrial network cooperation system of small and micro enterprises, and establish the docking mechanism of Guangdong-Hong Kong-Macau Greater Bay Area small and medium-sized micro enterprises based on the industrial chain.

\subsection{Strengthening external Communication and enhancing the ability of Bay area and International Dialogue Organization}

The government should organize official and semi-official international exchange projects in the Greater Bay area, guide and support all sectors of society to participate in or initiate useful international economic and cultural exchange dialogues, and strive to improve the quality of international exhibition and conference services. Improve the global dialogue transmission system and transmission mechanism. It is necessary to focus on projects or themes, consolidate the right to host major international and national exhibitions, expand new types of exhibitions in emerging industries and cultural, scientific and technological fields, and vigorously develop online exhibitions.

\subsection{Promoting the introduction of Enterprise headquarters and Industry organizations in Dawan Distric}

The government and enterprises should strengthen the introduction of international foreign-funded enterprises, strengthen the cultivation of the headquarters economy of local private enterprises, actively introduce the headquarters of important international chambers of commerce in line with Guangdong-Hong Kong-Macau Greater Bay Area's industrial characteristics, and gradually shape the status of leading cooperative organizers in some industries by registering the headquarters of national chambers of commerce.

\subsection{Constructing the Highland of talents in Guangdong, Hong Kong and Macao}

Development is the first priority, talent is the first resource, and innovation is the first driving force. Guangzhou has $60 \%$ of the undergraduate universities and more than half of the higher vocational colleges in Guangdong Province, and the number of colleges and universities is equal to that of Paris. Among them, the national "double first-class" first-class universities and 18 first-class disciplines in Guangdong Province are gathered in Guangzhou. Provincial key construction universities (or their main campuses) are located in Guangzhou, and 2/3 of the provincial key construction disciplines are also in Guangzhou. Guangzhou is also a major city with a net inflow of college graduates. According to the Times higher Education World University ranking, Hong Kong has three top 100 universities in the world. According to the QS World University rankings published by QuacquarelliSymonds, an educational organization, four universities in Hong Kong have entered the top 50 in the world. Compared with London, the United States, we should make good use of these conditions to speed up the construction of a national talent reform pilot area. Build Guangdong, Hong Kong, Macao and international talent port. It is also necessary to strengthen the building of the contingent of scientific and technological personnel and strengthen the training of entrepreneurs, including the training of "second-generation entrepreneurs" in private enterprises.

\section{Conclusion}

Based on scientific and technological innovation, institutional innovation and regional environmental innovation, starting with the sharing and integration of international resources in Guangdong, Hong Kong and Macao; based on the construction of advanced global high-end industrial agglomeration, international shipping and aviation integrated hub group, world economic, 
scientific and technological innovation and cultural information exchange position and high-level talent development environment; in-depth integration into the global first-tier urban agglomeration network, expand the global allocation of innovative resources, create the strength and characteristics of world-class urban agglomeration, and enhance the all-round and coordinated economic and social development of Guangdong.

\section{Acknowledgment}

This research was financially supported by the Key Research Platforms and Scientific Research Projects of Guangdong Province in 2018 (Young Innovative Talents) "Based on the Openness of Service Industry and Service Trade Innovation in the Pearl River Delta of Dawan District, Guangdong, Hong Kong and Macao"(Grant NO. 2018WQNCX261) and the Key Research Platforms and Scientific Research Projects of Guangdong Province in 2018 (Young Innovative Talents) "Research on Incentive Mechanism of Innovation Ecosystem Based on Guangzhou New Energy Automobile Industry" (Grant NO.2018WQNCX257).

\section{References}

1. D.Xu, Guangdong-Hong Kong-Macau Greater Bay Area Strategy and the Development of Port and Navigation Industry, Traffic and Port and Navigation, 2018(04):13-18.

2. J.P.Li, An Overview of Guangdong-Hong KongMacau Greater Bay Area and its Development pattern, China survey and design, 2018(05): 66-75.

3. The CPC Central Committee and the State Council, Outline of Guangdong-Hong Kong-Macau Greater Bay Area's Development Plan, 2019.2.18.

4. X.L.Dong, Relying on Guangdong-Hong KongMacau Greater Bay Area, constructing a New pattern of opening and Development in Foshan, Foshan Daily, 2018.5.22.

5. X.L.Chen, A probe into the Economic Development of Guangdong-Hong Kong-Macau Greater Bay Area, China market, 2019(08): 26-27, 43.

6. X.L.Dong, L.J.Chen,Carry forward the advance advantages of opening up and Development, and construct a New pattern of Open economy in Guangzhou,Urban observation, 2018(02): 62-81.

7. Z.Z.Zhang, Research on the Governance of intellectual property Rights of Guangdong-Hong Kong-Macau Greater Bay Area, Age of think tanks, 2018(29): 244-245. 